\section{EQUIPES ESPORTIVAS NO COLÉGIO ARQUIDIOCESANO SAGRADO CORAÇÃO DE JESUS: ANOTAÇÕES SOBRE A EXPERIÊNCIA DE JOGO COMO FORMAÇÃO}

\author{
SPORT TEAMS OF COLEGIO ARQUIDIOCESANO SAGRADO CORAÇÃO DE \\ JESUS: NOTES ABOUT GAME EXPERIENCES AS EDUCATION
}

EQUIPOS DEPORTIVOS EN EL COLEGIO ARQUIDIOCESANO SAGRADO CORAZÓN DE JESÚS: NOTAS SOBRE LA EXPERIENCIA DE JUEGO COMO FORMACIÓN

\section{Quéfren Weld Cardozo Nogueira*}

\section{Palavras-chave}

Esportes. Princípios

morais. Adolescente.
Resumo: 0 presente trabalho apresenta os relatos de uma observação participante realizada com equipes de voleibol em momentos de preparação e disputa de Jogos Escolares. $O$ objetivo foi o de compreender como uma proposta de educação moral se dinamiza na formação da experiência de jogo, em que é preciso gerenciar situações, buscar formas de reconhecimento e visibilidade e ampliar oportunidades de participação, as quais são, ao mesmo tempo, experiência de formação.

Abstract: This paper is a report on a participant observation undertaken with volleyball teams preparing to participate in School Games. The goal was to understand how a proposal of moral education is dynamized in game experiences, which demand managing situations, searching for ways of recognition and visibility, and enhancing opportunities for participation, which are also educational experiences.

Resumen: Este trabajo presenta los relatos de una observación participante realizada con equipos de voleibol en momentos de preparación y disputa de Juegos Escolares. El objetivo fue comprender cómo una propuesta de educación moral se dinamiza en la formación de la experiencia de juego, donde es necesario resolver situaciones, buscar formas de reconocimiento y visibilidad y ampliar las oportunidades de participación, que son, al mismo tiempo, experiencias de formación.
*Universidade Federal de Sergipe. Aracaju, SE, Brasil. E-mail: ufsquefren@gmail.com

Recebido em: 15-09-2014 Aprovado em: 01-07-2015 


\section{APRESENTAÇÃ $0^{1}$}

Como parte de um projeto cultural de produção do esporte como prática educacional, 0 treinamento de equipes estudantis é uma das principais estratégias pedagógicas para a prática esportiva nas escolas. Sessões de treinamento contemplam, sobretudo, as exigências de uma educação moral, pois a busca pela performance atlética intensifica o entendimento de que "todos aqueles que desejam ser atletas ou para serem atleta, devem seguir um axioma fundamental, a saber: não se é atleta sem obrigações morais" (CAMINHA, 2003, p. 64). A disputa de torneios esportivos, por sua vez, acompanha o pressuposto da "inutilidade de esperar a obtenção de marcas importantes sem um treinamento cotidiano, rigoroso e multiforme, que abranja o desenvolvimento de todas as qualidades físicas, nervosas e psicológicas" dos atletas (MOLLET, 1979, p. 57).

O presente texto apresenta o relato de experiência de uma observação participante realizada entre maio e novembro de 2012

- com as equipes masculina e feminina de voleibol do Colégio Arquidiocesano Sagrado Coração de Jesus, localizado na cidade de Aracaju (SE). Os treinamentos regulares foram analisados como "palco de experiências e contatos sociais" (MAGNANI, 2009), com destaque especial para o modo como a participação em práticas e treinamentos esportivos é parte do processo de construção da experiência de jogo como formação, compreendendo que a experiência de jogo "relaciona-se com a produção de imagens e significados para a vida social, participa da construção de noções de sujeito e de identidades, além de estabelecer relações sociais em que se cruzam vozes e histórias" (NOGUEIRA, 2013, p. 890).

A busca por performances mais elevadas constrói experiências que exercem a função pedagógica da cultura de construir identidades, mobilizar desejos e formar valores morais, 0 que significa afirmar como "a pedagogia ocorre onde quer que o conhecimento seja produzido, onde quer que a cultura receba a possibilidade de traduzir experiências e verdades construtivas, mesmo que essas verdades pareçam incessantemente redundantes, superficiais e triviais" (GIROUX, 1999, p. 253).

O trabalho foi dividido em três momentos: os primeiros encontros ocorreram para firmar acordo com a escola e identificar algumas peculiaridades da instituição; tratou-se de uma progressiva passagem de um momento inicial de estranhamento e pouca familiaridade com as pessoas e com o local para outro com liberdade para fazer indagações e mostrar-se mais atento a detalhes e acontecimentos. No segundo, a atuação como auxiliar técnico das equipes em preparação para disputarem os X Jogos Escolares da TV Sergipe, os XIX Jogos da Primavera e os XVII Jogos Interdiocesanos Norte e Nordeste (25 atletas, 13 meninas e 12 meninos, entre 14 e 17 anos) foi registrada em um caderno de campo, com anotações sobre o cotidiano dos treinamentos e filmagens de partidas oficiais. Nessa etapa, não apenas os alunos assumiam o papel de atletas, mas também eu devia cumprir a função de auxiliar técnico, cujo trabalho era compartilhado com outro auxiliar. Não houve entrevistas; o que ocorria eram diálogos sobre a temática esportiva, questões sobre a educação moral de atletas e as histórias e possibilidades de performance das equipes de voleibol do Arquidiocesano. No terceiro momento houve um distanciamento do local da pesquisa, o que permitiu transitar entre 
curtos períodos de afastamento e de retorno para apresentar relatório para a escola e avaliar o trabalho executado. O presente texto passou por duas avaliações prévias pelo Colégio: em dezembro de 2012, quando do encerramento da observação participante; e em março de 2015, após os pareceres para publicação enviados por esta revista.

\section{SOBRE O COLÉGIO ARQUIDIOCESANO}

O Colégio Arquidiocesano Sagrado Coração de Jesus está situado na quadra antigamente compreendida pelas ruas Riachuelo, Senador Rollemberg, Itabaiana e Pacatuba, terreno destinado para ser o Palácio Episcopal, à época de Dom José Thomaz Gomes da Silva, 1 - Bispo da Diocese de Aracaju, empossado em 3 de janeiro de 1910. Segundo Souza (2006), a opção em investir verbas públicas em empreendimentos religiosos, admitida na época pela Lei n. 534, permitiu que o Seminário Diocesano Sagrado Coração de Jesus, fundado em 4 de abril de 1913, possuísse sede própria, ao invés de se situar na residência do próprio Bispo, na Praça Camerino, 181. A fundação do Colégio ocorreu quando da permissão do 1ํ Arcebispo de Aracaju, Dom Vicente Távora, para que o Padre José Carvalho de Souza, então reitor do Seminário Arquidiocesano, fundasse o Educandário Diocesano S. Coração de Jesus, passando a Ginásio em 1960 e Colégio em 1963.

As torres eclesiásticas do Arquidiocesano destacam-se na paisagem do bairro São José, na região central de Aracaju. Abaixo das duas torres com cruzes em destaque no topo, uma imagem de Jesus Cristo ressuscitado sacraliza os tons vermelho e branco que ornam toda a arquitetura jesuítica, estendida por um renque de paralelas vermelhas entre típicas janelas de salas de aula. Seu símbolo - uma tocha olímpica em movimento, sobre uma Bíblia aberta no interior de um triângulo com base invertida de espessas bordas vermelhas - expressa o sentido esportivo da proposta de educação moral do Colégio, exposta na placa comemorativa quando da inauguração do Parque Polidesportivo Monsenhor José Carvalho de Souza:

Reconhecendo a importância do esporte para o desenvolvimento do corpo, como condição indispensável para o desenvolvimento do espírito, o COLÉGIO ARQUIDIOCESANO "S. CORAÇÃO DE JESUS" oferece aos seus alunos - atuais e futuros - este PARQUE POLIDESPORTIVO, constituído de PISCINAS SEMIOLÍMPICA E INFANTIL, GINÁSIO DE ESPORTE e CAMPO DE FUTEBOL, hoje, inaugurado sob as benções de DEUS, e advindas pelas mãos do EXM e REVM SR. DOM LUCIANO JOSÉ CABRAL DUARTE, ARCEBISPO METROPOLITANO DE ARACAJU.

Aracaju, 15 de junho de 1984.

Antes da visita ao Arquidiocesano pela primeira vez, algumas impressões sobre 0 Colégio já existiam: logo quando cheguei à cidade de Aracaju, em maio de 2009, percebi a importância das competições estudantis e do papel do Arquidiocesano para o esporte sergipano; lembro-me de um dos meus alunos do curso de Licenciatura em Educação Física da Universidade Federal de Sergipe (UFS) referir-se aos "Arqui-inimigos" como a principal escola a ser derrotada nos eventos esportivos. Concomitantemente, impressionava-me a efervescência dos Jogos da Primavera na cidade de Aracaju e no estado de Sergipe:

De maneira mais próxima, um evento esportivo na minha vida escolar foi de largo aprendizado e assento na memória, os Jogos da Primavera de Sergipe. Indo aos recônditos da memória, lembro-me de uma tarde de sábado no mês de setembro 
de 1987. Ao longo dos 900 metros da Avenida Barão de Maruim, no centro da cidade de Aracaju, milhares de pessoas iam se aglomerando em suas calçadas. Vindas de diversos pontos da cidade, inclusive de vários municípios do interior do estado, a população parecia deslocar-se toda para essa região. Trafegavam a pé, de automóvel, sobretudo de ônibus, tendo em vista que nesse dia, linhas exclusivas eram disponibilizadas para o povo. Esse ia se misturando aos vendedores ambulantes, policiais, bombeiros, agentes de saúde, distribuidores de panfletos políticos, e às autoridades políticas abancadas em um palanque no centro da avenida. Com isso a avenida coloria-se, mudava o aspecto sisudo do cotidiano, para dar passagem às cores e aos sons das escolas sergipanas, mas, essencialmente, dar passagem aos anseios e desejos de jovens estudantes, pais, diretores escolares e professores que seriam aquecidos nesse dia: o dia do desfile de abertura dos Jogos da Primavera. Desejos e anseios canalizados ao longo dos próximos doze ou quinze dias nas competições esportivas, a serem realizadas em diversos pontos da cidade (DANTAS JUNIOR, 2010, p. 18) [grifo do autor]

O contato com os XXVI Jogos da Primavera por meio de reportagens televisivas, ainda em 2009, fez aumentar o interesse em torno do Colégio. A matéria sobre a cerimônia de abertura, veiculada pela TV Sergipe, afiliada da Rede Globo, utilizou expressões como "a maior festa do desporto escolar" e "uma noite para ficar na memória". O número de escolas e de alunos que participaram dos Jogos - 378 escolas públicas e particulares, e mais de 13.000 estudantes - dava a dimensão do evento. 0 desfile de atletas, a presença do Governador do Estado na época, Marcelo Déda, o acendimento da pira olímpica, o juramento solene e a presença na cerimônia de abertura de atletas como Hugo Hoyama e Diego e Daniele Hypólito antecipavam a concretização de um evento inspirado no olimpismo.

$\mathrm{Na}$ reportagem de encerramento dos Jogos, o nome do Arquidiocesano apareceu como campeão geral daquela edição, com 47 medalhas de ouro, 51 de prata e 31 de bronze. Além das cores vermelha e branca que se destacavam nas bandeiras e nos uniformes dos alunos, foi o primeiro contato com Monsenhor Carvalho, diretor pedagógico e administrativo do Arquidiocesano na ocasião. As palavras do Cônego, ao invés de exaltarem a vitória em si, agradeciam aos alunos, professores, pais e avós que foram torcer pelo Colégio.

O Colégio Arquidiocesano Sagrado Coração de Jesus é designatório de uma instituição católica da rede particular de ensino, cuja meta filantrópica é a de formar cidadãos dignos, capazes e fiéis seguidores do Evangelho de Jesus Cristo. Pautado em valores como a fé, a verdade, a justiça, a solidariedade e 0 amor ao trabalho, o Arquidiocesano se tornou campeão dos Jogos da Primavera pela primeira vez em 1979, chegando em 2012 ao seu $19^{\circ}$ título. Tanto pela estrutura esportiva quanto por sua proposta pedagógica, o Arquidiocesano trazia a marca da esportivização da Educação Física, cujos meandros enfatizam a relação professor-treinador, aluno-atleta, aula-sessão de treinamento. Em 2012, a proposta pedagógica do Arquidiocesano indicava para os primeiros anos de escolaridade, do $1^{\circ}$ ao $3^{\circ}$ ano do ensino fundamental, atividades de Recreação Pré-Desportiva, quando os alunos entravam em contato com materiais e dinâmicas por meio de atividades com pouca ênfase na competição; no $4^{\circ}$ e $5^{\circ}$ ano eram oferecidas aulas de Iniciação Polidesportiva, para a experiência com diversas modalidades; do $6^{0}$ ao 9a ano, na fase denominada de Educação Física Desportiva, o aluno escolhia uma modalidade, de acordo com os conhecimentos previamente adquiridos; no ensino médio, com Atividades Esportivas de Alto Nível, os alunos integravam as equipes para disputar os Jogos Escolares e/ou outras competições estudantis. 
$O$ treinamento das equipes de voleibol ocorria três vezes por semana, cada uma com aproximadamente duas horas de duração, carga horária não equivalente para o componente curricular Educação Física. As sessões eram divididas em quatro momentos, com variações no tempo e intensidade no decorrer da periodização: preparação física; aquecimento específico; exercícios simples, em que apenas um fundamento era enfatizado; exercícios complexos, pelo treinamento simultâneo de diversos fundamentos técnicos. Com a proximidade das competições, os treinamentos físicos e técnicos eram gradativamente substituídos por exercícios de aplicação tática, focados em situações de jogo.

O objetivo pedagógico do treinador e professor de voleibol do Arquidiocesano era o de conciliar uma proposta humanista com outra tecnicista, desafio fruto do período de formação em Licenciatura em Educação Física, no início da década de 1980. Em sua avaliação, o tecnicismo fundamentava a aprendizagem dos aspectos técnicos e táticos do esporte, enquanto a tendência humanista apoiava uma proposta de educação pautada em valores morais. Nas preleções antes de jogos e treinamentos, as lembranças acerca dos elementos técnicos, como saque, bloqueio e defesa, eram perpassadas pela cobrança para dar o melhor de si, para fazer jus a todo o esforço empreendido nos treinamentos. Uma racionalidade técnica e instrumental acompanhada pela lembrança dos modos de conduta peculiares da condição de atleta reforçava os objetivos e motivações para disputarem a final dos X Jogos Escolares da TV SERGIPE:

\begin{abstract}
O meu sentimento é de confiança por tudo aquilo que nós construímos ao longo destes anos com maior dificuldade, e se hoje estamos aqui nessa final é mais do que merecido. $\mathrm{O}$ que importa é o que a gente conseguiu produzir nos treinos. Nós não temos que temer ninguém, nós estamos invictos, não sei se vocês perceberam, mas nós estamos invictos. A ordem é determinação; a ordem é acreditar sempre; concentração no saque, vocês têm oito segundos pra sacar, não têm que ir lá e estourar a bola, não! Se eu me posicionar na rede eu vou bloquear, no fundo vou defender, pode bater que eu vou pegar, o que eu puder fazer eu vou fazer. E é essa lição eu deixo pra vida de vocês, o que vocês quiserem fazer, façam agora. Pior coisa que pode acontecer na vida do ser humano é o arrependimento: poxa, eu poderia ter feito mais... já foi! Busquem sempre o seu melhor. Seja aqui, seja na sua vida profissional, na vida familiar. Essa é a lição que o esporte traz, toda uma formação de seres humanos. É isso o que eu quero, o melhor de vocês, seja o meu jogador principal até o décimo segundo jogador no banco. Todos, isso aqui é uma equipe, todos tem que estar prontos para darem o seu melhor em quadra. Ganhar ou perder é jogo, vocês têm que estar preparados pra tudo. Acreditem e façam isso agora acontecer. Não é impossível, é jogar bola. É ir pra cima, é pra arrebentar, não é pra deixar eles nem respirarem. Nós treinamos, nós treinamos para esse jogo, pra esse título (Raymundinho, técnico de voleibol do Colégio Arquidiocesano, 2012).
\end{abstract}

Antes das partidas, o grito de guerra repetido várias vezes, com ênfase na pergunta: "Quem somos nós?", iniciava o treinador; "Arquê", respondiam os alunos. "Quem somos nós? Arquê" repetido mais duas vezes e seguido por "Um, dois, três... união, raça, Arquê" construía um ambiente de pertencimento em que a produção de sentimentos coletivos é força propulsora para o desempenho esportivo. 0 professor se distinguia como fonte de motivação para a experiência esportiva, não para conduzir a equipe como um exército, nem para fazer da disciplina algo fácil e amável, mas compunha um tipo de relacionamento entre professor e aluno pautado em uma confiança amigável; um trabalho pautado em princípios como respeito ao nome do Arquidiocesano e orgulho em fazer parte dessa instituição; conhecimento das regras de disciplina e dedicação aos treinamentos; crença na capacidade de vencer, como 
fruto do processo de trabalho; criação de um ambiente agradável para os que estão dispostos a contribuir; valorização individual em nome do sucesso coletivo; utilização de histórias e experiências passadas para analisar situações do presente.

\section{FORMANDO EXPERIÊNCIAS DE JOGO}

As críticas a uma Educação Física esportivizada abordam o treinamento esportivo como um conjunto de práticas com poucas possibilidades para fomentar múltiplas formas de participação. Enquanto, para Kunz (1994), o esporte aliou-se a um tipo de racionalidade instrumental, produzida para o aperfeiçoamento físico-técnico de indivíduos vistos como objetos manipuláveis, na concepção de Soares et al. (1992), as características que revestem a performance esportiva (máximo rendimento atlético, comparação da performance, princípio da sobrepujança, regulamentação rígida e racionalização de meios e técnicas) atribuem valores educativos que inevitavelmente provocam e reproduzem as desigualdades sociais. As características do processo civilizador - pautadas em um alto grau de corrupção e alienação fazem com que o esporte tome para si aspectos desumanizadores, marcados pela "destruição paulatina do lastro de vida digna na sociedade" (TAFFAREL, 2009, p. 72).

Porém, a formação e o treinamento de equipes escolares oferecem um conjunto de oportunidades para os alunos circularem e se deslocarem entre as oportunidades de envolvimento e participação proporcionadas pela experiência da sociabilidade esportiva, no sentido de que "a sociabilidade, para os jovens, parece responder às suas necessidades de comunicação, de solidariedade, de democracia, de autonomia, de trocas afetivas e, principalmente, de identidade" (DAYRELL, 2007, p. 1111). Interpretando Gohn (2005) para o contexto deste trabalho, fazer parte de uma equipe esportiva exige uma relação do indivíduo com o universo simbólico daquela prática, como também a criação de ações individuais e coletivas, processos identitários, análise e reinterpretação de situações e fatos. $O$ aluno-atleta se apresenta como uma das "múltiplas expressões da juventude, que podem ser interpretadas dentro de um universo cultural específico" (CATANI; GILIOLI, 2008, p. 12), numa concepção em que ser jovem é tanto uma obrigação quanto uma possibilidade. Na multiplicidade de manifestações da condição jovem, encontramos uma "diversidade interna em termos de ethos, estilos de vida, visões de mundo, em geral, modos de construção social da realidade" (VELHO, 2005, p. 191).

Nas equipes de voleibol do Arquidiocesano há esportistas roqueiros, skatistas, modelos e músicos; são conectados com as redes sociais; escrevem poesias, têm dúvidas e opiniões políticas e religiosas. $\mathrm{O}$ início ou final dos treinamentos eram momentos para debater sobre os lances do treino daquele dia, as situações dos jogos passados, as melhores atuações e jogadas, como também as falhas ocorridas, as festas do final de semana, os trabalhos escolares ou os acontecimentos que ganharam destaque na mídia. Interesses e pontos de vista unem-se para compor uma equipe escolar, dinamizando assim o significado da experiência esportiva e fazendo das competições estudantis um ponto de encontro e de convivência social.

As práticas de treinamento esportivo promovem a formação da experiência de jogo, em que elementos técnicos e táticos das modalidades são aprendidos e aperfeiçoados. 0 grupo de participantes utiliza experiências e conhecimentos prévios sobre o esporte para avaliar a aplicabilidade das atividades sugeridas pelo treinador e o modo como se enxergam no interior de uma equipe esportiva. Durante o treinamento para os X Jogos Escolares da TV SERGIPE, 
na equipe masculina, o aluno atuante na posição de líbero deixou de fazer parte da equipe. 0 atleta escolhido para substituí-lo nunca havia treinado nessa função, o que o incentivou a cobrar a realização de exercícios de passe e defesa, deixando de lado 0 ataque e o saque. Diante desse novo desafio, era comum o novo líbero chegar antes do horário do treino e solicitar que alguns dos auxiliares técnicos desenvolvessem exercícios de passe e defesa.

Não apenas as duas horas de treinamento eram utilizadas para algum tipo de envolvimento com o voleibol. Na segunda-feira, os treinos das duas equipes ocorriam em sequência: das $18 \mathrm{~h}$ às $20 \mathrm{~h}$, o horário era da equipe feminina; logo após, das $20 \mathrm{~h}$ às $22 \mathrm{~h}, \mathrm{a}$ masculina estava em quadra. Chegar antes do treino permitia a execução de alguma atividade específica do voleibol, como ataque e defesa, ou realizar arremessos para a cesta de basquete ou participar de um "baba", isto é, um jogo esportivo informal. Era possível também brincar com os fundamentos, sem uma preocupação em transformar aquilo em uma atividade de aperfeiçoamento técnico.

Algumas atletas procuravam estender o tempo de treino: duas delas decidiram aprender como sacar "viagem" e aproveitaram a oportunidade para executar esse tipo de saque, pedindo para serem observadas e corrigidas em prováveis imperfeições. Com o intuito de melhorarem essa habilidade, permaneciam após o treino, adentrando no horário da equipe masculina. Tal situação perdurava até o momento em que alguns meninos começavam a lembrá-las de que o treino delas havia acabado. Encerrar um treinamento não significava ir para casa, pois, caso houvesse alguma atividade em andamento, era comum permanecerem por mais tempo na escola. Tanto os meninos chegavam mais cedo para assistir ao treino das meninas e, talvez, participar de algum exercício ou jogo, quanto as meninas permaneciam por um período maior, não apenas para treinar, mas para se fazer presentes naquele espaço social.

Os horários estabelecidos não impediam as diversas possibilidades de utilizar o tempo para se envolver com o voleibol, com as pessoas e com práticas culturais que porventura pudessem surgir, como música ou contação de histórias. Estar na quadra antes do horário marcado e permanecer após o treino permitia dialogar, encontrar atletas de outras modalidades, marcar encontros para decidir questões sobre matérias escolares, como trabalhos que deveriam ser entregues, combinar encontros em shows e festas, fazer comentários sobre os acontecimentos do dia, etc. Em um dia específico, um dos atletas da equipe de voleibol trouxe um violão, já que naquele dia houve um ensaio para um festival de música que aconteceria nas próximas semanas. Após o término do treino, um banco extenso nas proximidades da quadra, ao lado do bebedouro, se tornou um local de cantoria e histórias.

A produção de um sentimento coletivo ornamenta um trabalho perpassado por níveis diferenciados de seriedade e divertimento. A linha divisória entre ambos é sutil: uma piada ou frase de impacto, alguma situação engraçada, a visita de algum ex-atleta, etc. faziam surgir situações descontraídas. O levantador da equipe masculina era assíduo e pontual nos treinamentos, além de não perder uma chance de treinar com a equipe feminina; porém, as aparições em outras aulas não eram tão constantes. A justificativa era: "a aula é chata, o treinamento não!". Disciplina e seriedade não são empecilhos para o divertimento, mas formam uma profícua parceria. $O$ treino fica ruim quando deixa de ser dinâmico, quando nem todos se esforçam e quando muitos erros são cometidos. O aperfeiçoamento técnico se torna condição para uma relação positiva com o jogo, não havendo uma distância tão nítida entre as práticas de treinamento e uma relação lúdica com as possibilidades de participação esportiva. 
Como no estado de Sergipe a visibilidade esportiva é focada principalmente nos esportistas estudantis, os atletas sabem de que se trata de uma participação que se findará quando do término das competições escolares, ou quando atingirem determinada idade em que não será mais possível disputar esses torneios. 0 desejo e o empenho em melhorar os fundamentos técnicos, além de entusiasmar com as oportunidades de participação, constroem um espaço de visibilidade e reconhecimento, manifestações parceiras nos Jogos Escolares. Não é possível apontar aqui lutas antirracistas ou anti-homofóbicas, por exemplo, em função da inclusão simbólica e econômica de grupos discriminados; estamos distantes de preocupações como ausência de emprego, condições precárias de vida, alto custo das atividades artísticas e culturais. 0 distanciamento dessas questões é expresso nas poucas alusões sobre as possibilidades de ascensão social pelo esporte, pelo menos no sentido socioeconômico. Duas alunas foram apontadas como possíveis candidatas a integrarem equipes profissionais; todavia, uma delas não se interessou por essa profissão; outra teve a oportunidade de compor equipes juvenis em um estado do Sudeste, mas decidiu voltar para sua cidade natal, Aracaju, com a justificativa de que "essa vida não é pra mim".

A noção de visibilidade se aproxima dos benefícios simbólicos de estar em evidência. Como parte da tentativa de se tornar visível em determinado segmento da juventude, a autoavaliação por parte dos alunos recaía sobre "como joguei?", "você viu aquela bola que eu ataquei?", "e aquela defesa?". Não como um interesse mesquinho ou vulgar, mas como uma especificidade do modo de ser jovem que busca atenção e reconhecimento para as suas ações. Nas palavras de uma atleta: "O esporte é uma forma de estar no meio social, né? Querendo ser notado a partir dele e aproveitando a sua juventude".

No interior de uma equipe esportiva existem relações diferenciadas em um grupo que se mostra heterogêneo. Existe uma relação com a situação de titular ou reserva: há aqueles que se enxergam como titulares absolutos, cuja vaga não está ameaçada; aqueles que sabem que ainda não têm habilidades suficientes para tomar a vaga de jogadores mais velhos; outros querem apenas jogar, o que significa treinar com a equipe ou ter a oportunidade de entrar em quadra quando a equipe adversária não apresentar dificuldades. Os alunos recorrem a diversas questões para justificar sua presença no grupo de atletas: marcar pontos é sinal de estar ali não para "tapar buraco", mas para contribuir, o que pode, posteriormente, trazer elogios ou comentários sobre a atuação. A avaliação recai sobre como a oportunidade de estar em quadra foi ou não desperdiçada, e que é preciso atentar para situações capazes de impressionar o treinador para garantir uma vaga nos próximos jogos.

No caso daqueles que se destacam tecnicamente, é importante serem reconhecidos como sendo decisivos para o resultado positivo do jogo. Ataques mais potentes são motivo de elogios e comparações com atletas profissionais. Jogar bem significa construir um sentimento de confiança em si mesmo e fugir do nome pejorativo de "pipoqueiro", isto é, um tipo de jogador que falha em momentos decisivos do jogo. Nos debates sobre as opções táticas ocorriam alusões sobre como cada um se enxergava no interior da equipe: há situações como levantadores que querem se tornar atacantes, com a justificativa de que o levantador é pouco visto e elogiado. Compreender melhor a tática é também um processo de avaliação pessoal sobre o tipo de relação que cada um quer ter com o jogo e sobre sua presença como membro de uma equipe.

A característica educacional do esporte de se apresentar como um campo em que há diversão e alegria, mas, também, dificuldades e problemas (VISÃO..., 1991, p. 35) contempla 
a capacidade de gerenciar situações. As situações de conflito eram pouco frequentes, penso que pela própria trajetória do Arquidiocesano em trabalhar sob a influência do professor como autoridade moral. Como seria possivvel não haver conflitos e discordâncias? Onde estavam as discussões ou estresses provocados pela cobrança constante pelo aumento do rendimento? Ao buscar a explicação para tal fato, descobri uma situação atípica: por causa de desavenças ocorridas em anos anteriores, a equipe feminina chegou à conclusão de que era preciso focar nos interesses coletivos. Na partida final de um dos torneios, no entusiasmo das comemorações pela vitória, o grupo de alunas se reuniu no centro da quadra, e uma das atletas afirmou que a ausência de atritos e o espírito de equipe foram os ingredientes principais da vitória: "São cinco anos de voleibol no Arqui, é o primeiro que não houve confusão, o primeiro que não brigamos, porque isso aqui é uma equipe".

A equipe masculina no Arquidiocesano, campeã dos XXVIII Jogos da Primavera, tinha a fama de polêmica, com jogadores com destaque no cenário esportivo juvenil sergipano, tanto no vôlei quanto no futebol. No ano seguinte, em 2012, a equipe era formada por poucos atletas desse time vencedor e polêmico. Muitos dos alunos atuais estavam em seu primeiro ano na categoria juvenil, deixando para trás antigos companheiros ainda da categoria infantil. $\mathrm{O}$ que poderia ser notado era a formação de subgrupos por causa da idade ou tempo na categoria, sem que isso fosse um problema para o andamento do treino. Aconteciam situações como brincar de brigar, na intenção de imobilizar o adversário. Não houve em nenhum momento socos ou ferimentos, e os participantes da peleja não saíram feridos. O que ocorria eram comentários e piadas, felicitações para golpes bem executados e argumentos sobre quem realmente venceu a disputa. Tudo isso sendo acompanhado pelo professor, que logo retomava o foco da preparação.

Temos no cotidiano do treinamento alunos que utilizam referências distintas para interpretar e gerenciar situações. O dia a dia de preparação para os torneios oportuniza acontecimentos que estão além das questões que um manual de treinamento esportivo se propõe a descrever: em um treinamento da equipe feminina, diversas ex-alunas-atletas do Arquidiocesano marcaram um encontro na escola para treinarem com a equipe atual, participando das mesmas atividades, retomando sua condição de integrantes da equipe. Quando da chegada de cada ex-aluna, a recepção era cada vez mais calorosa, com abraços no treinador e apresentação delas para o restante do grupo. Era também um momento para relembrar pequenas histórias, viagens realizadas e títulos conquistados. Como alguns atletas da equipe masculina já haviam chegado ao ginásio, o treino contou com a participação de exatletas, atletas das equipes feminina e masculina atuais, além dos treinadores e assistentes técnicos que participaram das atividades. Ou seja, naquele treino se uniram quatro ou cinco gerações para a prática do voleibol, o que fez do treinamento um espaço de contatos múltiplos, com relatos sobre jogos e acontecimentos passados e o significado da experiência com 0 esporte.

\section{CONCLUSÃO}

Nos XIX Jogos da Primavera a equipe masculina foi derrotada no final do torneio e a feminina sagrou-se campeã. Os processos para tais equipes disputarem a final de um torneio estudantil nos permitem afirmar as práticas de treinamento tanto favoráveis para 
adaptações progressivas ao esforço como incentivadoras de práticas de sociabilidade juvenil. O esporte se torna um instrumento para o estabelecimento de relações sociais que têm como referência o modo de ser jovem, permitindo que os esportistas gerenciem situações, busquem reconhecimento e visibilidade e ampliem a possibilidade de participação. Olhar para o treinamento esportivo de equipes escolares para tachá-lo de pouco educativo por se pautar no esporte de rendimento também pouco nos diz sobre a formação da experiência de jogo e 0 lugar dos alunos-atletas nesse processo.

Na experiência esportiva aqui relatada, o conteúdo da moral afeta a nossa sensibilidade, pois nos identificamos com as prescrições morais oferecidas. As regras morais se apresentam menos como um código de deveres e mais como um bem que nos cativa. Um código moral perseguido porque se apresenta como bom tem prestígio e energia para supor que a regra em si, o modo como a percebemos, justificamos e respeitamos, é para nós objeto de desejo. A moral apresenta esse duplo aspecto de ser um bem e um dever: "aqui reclama de nós uma completa obediência, lá, como um magnífico ideal ao qual a sensibilidade aspira espontaneamente" (DURKHEIM, 2008, p. 104). O bom-mocismo, descrito por Fraga (2000) como uma marca que se distingue no bom-cristão, bom-chefe de família, bom-aluno, bom-cidadão, bom-partido, bom-empregado, é destacado no aluno-atleta que pratica esporte como fonte de experiências e contatos sociais.

O conjunto de esforços pedagógicos e os investimentos políticos nos Jogos Escolares nos impedem de tratar eventos desta magnitude como aquém de intenções educativas. Não se trata de situar o treinamento esportivo como um reflexo da dimensão de rendimento adentrando no cotidiano escolar, mas, sim, de reconhecer tanto os limites quanto as possibilidades do esporte em fomentar propostas educativas. Os elementos destacados por Bracht, (1997) como participação, contatos sociais, formação de subgrupos, resolução de conflitos, aceitação, mudança e expressão de regras, nos colocam diante de uma prática que traz consigo a oportunidade de realizar experiências positivas de participação para o reconhecimento de potencialidades e criação de mecanismos de envolvimento coletivo.

$\mathrm{O}$ desenvolvimento de capacidades físicas e a aprendizagem de habilidades motoras, a motivação para o esporte, a melhoria do desempenho e o domínio das técnicas e táticas são instrumentos para o trabalho com conhecimentos, relações sociais e modos de comunicação em que se formam e se cruzam histórias e experiências de vida. Fazer parte de uma equipe esportiva exige a formação de experiências de jogo em que é preciso gerenciar situações, buscar formas de reconhecimento e visibilidade e ampliar as oportunidades de participação, as quais são, ao mesmo tempo, processos da experiência de jogo como formação.

Se, por um lado, é constatado que a escola não tem se adequado para reconhecer o aluno como jovem (CAMACHO, 2004), por outro, participar de Jogos Escolares coloca determinado segmento da juventude em evidência, o que pode servir para fazer desses eventos um espaço para compreender de maneira mais profícua os anseios e necessidades tanto dos jovens esportistas quanto de outras expressões sociais da juventude.

Tais questões dinamizam uma suposta rigidez da experiência e da moralidade esportiva. A meta das escolas em ganhar títulos ou se destacar nos quadros de medalhas não é uma preocupação primordial para os alunos-atletas, mas a formação de uma experiência que dá o sentido à sua própria condição como jovem que participa de acontecimentos da vida social. 0 treinamento esportivo coloca o aluno-atleta em contato com uma moralidade inicialmente dada 
como coerente e imutável, mas que se dinamiza no processo de legitimação e significação das práticas sociais. Os exercícios repetitivos de melhoria da aptidão física e aperfeiçoamento técnico e tático estão inseridos em um ambiente que permite reinterpretações, pois dizem respeito ao modo como são criadas expectativas e experiências individuais e coletivas. Por meio dessas experiências surgem situações de envolvimento coletivo, que fazem das atividades de aperfeiçoamento técnico e tático um subsolo para possibilidades de participação como forma de vivenciar a condição jovem com características lúdicas e de lazer.

\section{REFERÊNCIAS}

BRACHT, Valter. Educação física e aprendizagem social. Porto Alegre: Magister, 1997.

CAMACHO, Luiza Mitiko Yshiguro Camacho. A invisibilidade da juventude na vida escolar. Perspectiva, Florianópolis, v. 22, n. 2, p. 325-343, jul./dez. 2004.

CAMINHA, Iraquitan de Oliveira. Considerações sobre a "ética do esporte". In: LUCENA, Ricardo de Figuereido.; SOUZA, Edilson de. Educação Física, esporte e sociedade. João Pessoa: Editora Universitária/UFPB, 2003.

CATANI, Afrânio Mendes.; GILIOLI, Renato de Sousa Porto. Culturas juvenis: múltiplos olhares. São Paulo: Editora UNESP, 2008.

DANTAS JUNIOR, Hamilcar Silveira. Jogos da Primavera de Sergipe: tradição, espetáculo e "esportivização da escola" (1964-1995). São Cristóvão-SE: Editora UFS, 2010.

DAYRELL, Juarez. A escola "faz" as juventudes? Reflexões em torno da socialização juvenil. Educação \& Sociedade, Campinas, v. 28, n. 100, p. 1105-1128, out. 2007.

DURKHEIM, David Émile. A educação moral. Petrópolis: Vozes, 2008.

FRAGA, Alex Branco. Corpo, identidade e bom-mocismo: cotidiano de uma adolescência bem comportada. Belo Horizonte: Autêntica, 2000.

GIROUX, Henry. Cruzando as fronteiras do discurso educacional. Porto Alegre: Artmed Editora, 1999.

GOHN, Maria da Glória. O protagonismo da sociedade civil: movimentos sociais, ONGs e redes solidárias. 2.ed. São Paulo: Cortez, 2008.

KUNZ, Eleonor. Transformação didático-pedagógica do esporte. ljuí: Unijuí, 1994.

MAGNANI, José Guilherme Cantor. Etnografia como prática e experiência. Horizontes Antropológicos, Porto Alegre, v. 15, n. 32, p. 129-156, jul./dez. 2009.

MOLLET, Raoul. À procura de soluções sociais. In: MOLLET, R. Treinamento ao ar livre: cross-promenade. São Paulo: Lince, 1979. p. 57-98.

NOGUEIRA, Quéfren Weld Cardozo. Esporte e a experiência de jogo como formação.

Educação \& Realidade, Porto Alegre, v. 38, n. 3, p. 873-893, jul./set. 2013. 
SOARES, Carmem Lúcia et al. Metodologia do ensino da educação física. São Paulo: Cortez, 1992.

SOUZA, José Carvalho de. Presença participativa da Igreja Católica na história dos 150 anos de Aracaju. Aracaju: Gráfica J. Andrade, 2006.

TAFFAREL, Celi Nelza Zulke. Desporto Educacional: realidade e possibilidades das políticas governamentais e das práticas pedagógicas nas escolas públicas. In: STIGGER, Marco Paulo; LOVISOLO, Hugo. (Org.). Esporte de Rendimento e Esporte na Escola. Campinas: Autores Associados, 2009. v. 1, p. 71-102.

VELHO, G. Juventudes, projetos e trajetórias na sociedade contemporânea. In: ALMEIDA, M. I. M.; EUGENIO, F. Culturas jovens: novos mapas do afeto. Rio de Janeiro: Zahar, 2005. p. 192200.

VISÃO didática da educação física: análise críticas e exemplos práticos de aula. Rio de Janeiro: Ao Livro Técnico, 1991. 